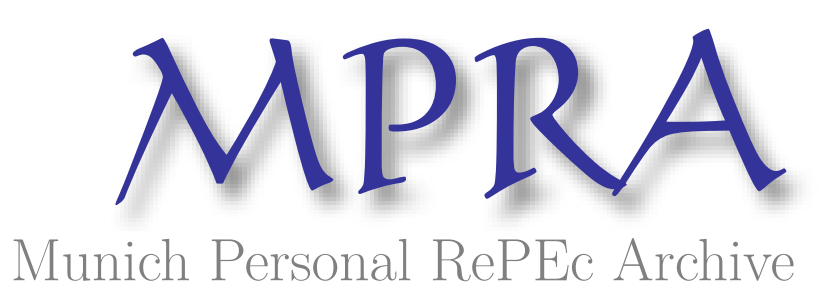

\title{
Effective Protection in the Presence of Joint Production
}

Londero, Elio

November 1999

Online at https://mpra.ub.uni-muenchen.de/100484/

MPRA Paper No. 100484, posted 18 May 2020 21:27 UTC 


\title{
EFFECTIVE PROTECTION IN THE PRESENCE OF JOINT PRODUCTION
}

\author{
by Elio Londero *
}

November, 1999

\begin{abstract}
This paper analyzes the measurement of effective protective rates when there is joint production. It shows that special attention is required when tradables are jointly produced with nontradables, and especially when there are significant changes in the prices of nontradables. Input-output formulas for the Balassa and Corden methods are provided.
\end{abstract}

J.E.L. classification number: F13, D57

Keywords: effective protection, joint production

* This is the accepted manuscript of an article published in the Journal of Economic Studies, 28 (1), 34-43, 2001. DOI: https://doi.org/10.1108/01443580110361454. This article is $(C)$ Emerald Publishing Limited and permission has been granted for this version to appear here: https://mpra.ub.uni-muenchen.de. Emerald does not grant permission for this article to be further copied/distributed or hosted elsewhere without the express permission from Emerald Publishing Limited. 


\title{
EFFECTIVE PROTECTION IN THE PRESENCE OF JOINT PRODUCTION
}

\author{
by Elio Londero *
}

\section{Introduction}

Conventional formulas for calculating effective protective rates normally assume singleproduct activities. In a recent paper, Greenaway, Reed and Hassan (1994) considered the existence of by-products and came to the conclusion that "their inclusion can make a significant difference to estimated effective protection coefficients" and that by-products "should be included in effective protection calculations" (p. 36). This paper restates the traditional argument on why all joint products "should be included", and argues that no basis exists for calculating separate effective protective rates for each joint output. Based on the premise that it is the productive activities of firms, not specific goods, what are being protected by imposing tariffs on their outputs, the paper provides the input-output formulas for estimating effective protective rates under the Balassa and Corden methods when there is joint production in fixed proportions. ${ }^{1}$ These formulas incorporate the price effects of changes in the supply of the joint outputs, and are based on input-output descriptions of tradable activities and their interrelationships with all other activities under the assumption that physical coefficients are the same in the protected and in the free trade situations. The paper concludes that the existence of joint production does require special attention, particularly when there is joint production with nontradable goods.

\section{What Is Being Protected?}

The protective effect of a tariff is the incentive that, given the tariff structure, is given to firms by the imposition of a tariff for developing or increasing the production of a tradable output. The effective protective rate (epr) is a way of measuring that incentive, by which value added in the protected situation is compared to that in the (hypothetical) free trade situation.

When a tradable output can be produced by only one single-output activity, a condition 
implicitly assumed in many studies, it becomes operationally innocuous to speak of the epr of the output, since output and activity are biunivocally associated. However, such is no longer the case when there are more than one single-output techniques to produce that output. A tariff levied on a specific good may generate as many epr as there are techniques to produce it.

When a tradable output is produced jointly with others, the protective effect of a tariff levied on one of the outputs is an effect on the activity, since it is not possible to provide the protection incentive to producing that output without providing it to producing the other joint outputs. ${ }^{2}$ From a practical point of view, the epr cannot be measured independently for one joint output, since by definition costs cannot be attributed by output. Therefore, estimating epr for individual, though jointly-produced outputs, would be incorrect. It would be possible, however, to calculate the epr that the tariff levied on that same good provides to a different single-output activity that produces it.

A corollary of these definitions is that an activity's epr would be the result of the individual tariffs applied to its inputs and outputs, and would depend on its cost structure and output basket. A change in the tariff levied on one output will affect the epr enjoyed by all activities that produce that output. Thus, it would be possible to measure the change in an activity's epr that is attributable to a change in the tariff levied on one of its joint outputs.

\section{Balassa's Method}

Following the idea that activities are protected by tariffs levied on their outputs, interest has been placed on estimating the incentive received by these activities and resulting from the overall tariff structure. Since protection increases value added by the tradable activity per unit of output, Balassa's $(1971,1982)$ method aims at measuring that additional value added generated directly by the activity and attributable to the protective structure. ${ }^{3}$ It is only interested in the incentive that protection grants to the protected activity, excluding that part of the total incentive that leaks to its providers of nontradable inputs. Since supply functions of nonproduced inputs are normally upwardly sloped, protection would also increase the per unit value added by the providers of nontradable inputs, reducing the incentive to those activities that are intensive in those nonproduced inputs whose price rise the most. 
Following Balassa's approach, the effective rate of protection to single-output activity $c$ may be calculated as the excess of the value added by $c$ in the protected situation over the value added in the free trade situation, expressed as a proportion of the value added in the free trade situation

$$
e p r_{c}^{B}=\left[\frac{\left(1-\sum_{s} a_{s c}-\sum_{i} a_{i c}\right)\left(p_{n}^{f} / p_{n}^{p}\right)}{\frac{(1+\delta)}{\left(1+t_{c}\right)}-\sum_{s} a_{s c} \frac{(1+\delta)}{\left(1+t_{s}\right)}-\sum_{i} a_{i c}\left[\sum_{s} \sum_{k} r_{k i} a_{s k} \frac{(1+\delta)}{\left(1+t_{s}\right)}+\sum_{v} \Sigma_{k} r_{k i} f_{v k} z_{v}\right] \mid} \mid-1\right.
$$

where $a_{s c}$ and $a_{i c}$ are the value of tradable input $s$ or nontradable input $i$ per unit value of tradable output $c$ in the protected situation; $p_{n}^{f}$ and $p_{n}^{p}$ are the prices of the numeraire commodity $(n)$ in the free trade $(f)$ and protected $(p)$ situations, respectively; $\delta$ is the devaluation of the domestic currency required to reach the equilibrium exchange rate in the free trade situation; $t_{c}$ and $t_{s}$ are the tariff rates on output $c$ and tradable inputs $s$, respectively; $r_{k i}$ is the value of direct and indirect requirements of input $k$ per unit value of output $i ; a_{s k}$ is the value of tradable input $s$ per unit value of tradable output $k$, in the protected situation; $f_{v k}$ is the value of nonproduced input $v$ per unit value of output $k$; and, $z_{v}$ is the ratio of the free-trade to the protection price of nonproduced input $v$.

The numerator of equation [1] is value added by the activity in the protected situation, multiplied by the relative prices of the numeraire. The denominator is value added by the activity in the free trade situation; ${ }^{4}$ thus, it does not include the per unit value added by the rest of the economy in producing nontradable inputs $\left(\Sigma_{v} \Sigma_{k} r_{k i} f_{v k} z_{v}\right)$, which is deducted from the price of the output. Note that measuring the value added by the activity in the free trade situation requires to estimate the ratios of prices of nonproduced inputs in the free trade to those in protected situation $\left(z_{v}\right)$. Since these estimates are difficult to produce, and are not deemed reliable, in practice, Balassa's measure is calculated under the assumption that nontradables are "supplied at constant costs, where the cost of nontraded inputs is affected by protection-induced changes in the prices of tradable inputs used in the production of nontradable goods" (Balassa, 1982, p. 15), that is, under the assumption that $z_{v}=1$ for al $v$. 


\section{Resource Pulls and Corden's Method}

While it is activities that are protected by imposing tariffs on their outputs, the effects of that protection are not confined to the activity. Protection to an activity would also grant an incentive to increasing the production of its nontradable inputs, pulling resources towards that input-output chain. ${ }^{5}$ Consequently, additional value added by the economy through the protected tradable activity and attributable to the protective structure may be conceptually decomposed into that generated in the protected activity (measured by the Balassa method) and that generated in supplying its nontradable inputs. This distinction lies behind the two best-known methods for measuring effective protective rates when there are nontradable inputs. While Balassa's method is concerned with the incentive to (additional value added by) the activity, Corden's $(1966,1971,1975,1985)$ method tries to measure the incentive attributable to protecting the activity and provided to (additional value added by) the economy to reallocate resources towards a particular input-output chain; that is, the extra value added by the tradable activity and by its direct and indirect suppliers of nontradable inputs. The two methods measure different things.

As a measure of the incentive to reallocate resources provided to the economy through the protection of single-output activity $c$, Corden's measure comprises not only value added by the activity, but also value added originating in the linkages between the tradable product and its nontradable inputs. In other words, coefficients $a_{i c}$ in the numerator of equation [1] should be decomposed backwards into their total requirements of tradable inputs and domestic value added, and then only the total requirements of tradable inputs should be deducted from the value of the product. In the denominator, instead, value added at international prices (in the domestic currency) would be the value of the output less total requirements of tradable inputs, everything valued at free trade prices. Consequently, the effective protective rate of single-output activity $c$ would be 


$$
e p r_{c}^{C}=\left[\frac{1-\Sigma_{s} a_{s c}-\Sigma_{i} a_{i c} \Sigma_{s} \Sigma_{k} r_{k i} a_{s k}}{\frac{(1+\delta)}{\left(1+t_{c}\right)}-\sum_{s} a_{s c} \frac{(1+\delta)}{\left(1+t_{s}\right)}-\sum_{i} a_{i c} \Sigma_{s} \Sigma_{k} r_{k i} a_{s k} \frac{(1+\delta)}{\left(1+t_{s}\right)}} \mid \frac{p_{n}^{f}}{p_{n}^{p}}-1\right.
$$

The numerator of equation [2] is value added by the activity in the protected situation, plus total requirements of value added in producing the nontradable inputs required to produce $c$ (and not just value added by activity $c$ ), equaling one less the direct and indirect requirements of tradable inputs. The denominator is the equivalent measure for the free trade situation, that is the value of the product less total requirements of tradable inputs, all valued at free trade prices.

Corden's measure for single-output activities does not require to estimate the price ratios for nonproduced inputs (other than the real rate of depreciation with respect to the numeraire good) because under the assumption of fixed physical coefficients the total value added (by the activity and its suppliers of nontradable inputs) is obtained as a residual. ${ }^{6}$

\section{Effective Protection in the Presence of Joint Production}

The joint production of tradable goods should make no difference in measuring the epr according to the Balassa method, since what we intend to measure is the incentive to the activity granted through the protection of its tradable outputs. Calculations would be made using equation [1] adjusted for the existence of more than one tradable output, that is

$$
1+t_{c}=\Sigma_{m} \varsigma_{m}\left(1+t_{m}\right)
$$

where $\varsigma_{m}$ is the participation of tradable output $m$ in total value of production at world prices, and coefficients $a_{s c}$ and $a_{i c}$ have been calculated as proportions of total value of production by the activity.

Measurement under the Corden method would also be carried out according to expression [2] as long as all joint outputs are tradable. As in the Balassa method, the only difference with the 
single output case would be the need to estimate the average tariff of the tradable basket according to equation [3].

In practice, industry (rather than activity) estimates prepared according to simplified versions of equations [1] and [2], as corrected by [3], are common. ${ }^{7}$ What is not clear in those estimates is the treatment given to nontradable joint outputs, and the reader is frequently left with the impression that nontradable outputs have been pooled with traded ones and treated as such. ${ }^{8}$ The remainder of this article is devoted to the treatment of nontradable joint outputs. ${ }^{9}$

When there are nontradable outputs, Balassa's formula for calculating value added by the activity in the free trade situation $v a_{c}^{f B}$ would have to be adjusted to take into account the effects of the change in the price of the nontradable joint output. As a result, value added by the activity in the free trade situation, expressed in the numeraire, would be estimated as

$$
\begin{aligned}
& v a_{c}^{f B}=\left[\frac{\left(1-a_{b}\right)(1+\delta)}{\left(1+t_{c}\right)}+\alpha_{b} z_{b}-\Sigma_{s} a_{s c} \frac{(1+\delta)}{\left(1+t_{s}\right)}-\right. \\
& \left.\quad-\sum_{i} a_{i c}\left[\sum_{s} \Sigma_{k} r_{k i} a_{s k} \frac{(1+\delta)}{\left(1+t_{s}\right)}+\Sigma_{v} \Sigma_{k} r_{k i} f_{v k} z_{v}\right]\right] \frac{1}{p_{n}^{f}}
\end{aligned}
$$

where $\alpha_{b}$ is the participation of nontradable basket $b$ in total value of production of activity $c$ in the protected situation, $z_{b}$ is the ratio of the free trade price of $b$ to that in the protected situation, $t_{j}$ is the average tariff for the tradable basket (calculated according to equation [3]), and coefficients $a_{s c}$ and $a_{i c}$ have been calculated as proportions of total value of production by the activity, including tradable and nontradable outputs.

In the case of Corden's method, the incentive to domestic value added by the economy provided through protecting the tradable joint outputs would be affected by the additional supply of the nontradable joint output with respect to the free trade situation. There would be two effects on 
value added in the production of nontradable goods that would be attributable to protection: i) an increase in value added originating in the production of inputs for the protected activity, and ii) a reduction in value added by other suppliers due to the price reduction originating in the additional supply of the nontradable good that is obtained jointly with the tradable good. ${ }^{10}$

If the nontradable joint output is not produced at the margin by other activities, the only direct effect originated in the protective structure would be to change the price of the nontradable. That price change would lead to computing two effects in the denominator of equation [2]. First, the effect on the unit value of the output basket, which was discussed for the Balassa method. Second, since Corden's method aims at measuring changes in value added by the economy, account should be taken of the change in value added by all sellers of output $b$ other than activity $c$. Thus, value added by nontradable activities in the free trade situation should be adjusted for the price change in the nontradable output that is attributable to protecting the tradable activity, times the total quantity sold in the free trade situation, expressed per unit of total value of production of activity $c$.

Following the usual approach of starting from the protected situation, and assuming that $c$ is the only tradable activity jointly producing $b$, the price effect may be estimated as

$$
\left(z_{b}-1\right) \varphi_{b}=\left(z_{b}-1\right) \frac{p_{b}^{p} \Sigma_{j \neq c} Q_{j b}^{f}}{X_{c}^{p}}
$$

where $z_{b}$ is the ratio of the free trade price of $b$ to that in the protected situation, $p_{b}^{p}$ is the price of $b$ in the protected situation, $Q_{j b}^{f}$ is the quantity of $b$ sold in the free trade situation by all activities $j$ except $c,{ }^{11}$ and $X_{c}^{p}$ is total value of production of activity $c$ in the protected situation. Consequently, value added by the economy in the free trade situation, expressed in the numeraire, would be 


$$
\begin{aligned}
v a_{c}^{f C}=\left[\frac{\left(1-\alpha_{b}\right)(1+\delta)}{\left(1+t_{j}\right)}+\alpha_{b} z_{b}-\Sigma_{s} a_{s c} \frac{(1+\delta)}{\left(1+t_{s}\right)}-\right. \\
\left.\quad-\sum_{i} a_{i c} \Sigma_{s} \Sigma_{k} r_{k i} a_{s k} \frac{(1+\delta)}{\left(1+t_{s}\right)}+\left(z_{b}-1\right) \varphi_{b}\right] \frac{1}{p_{n}^{f}}
\end{aligned}
$$

If there were more than one tradable activity jointly producing $b$, only part of the price reduction $p^{p}-p^{f}$ would be attributable to activity $c$, and it is not clear how that part could be estimated other than distributing the price change proportionally to the changes in the supply of $b$ by tradable activities.

It is appropriate now to pause and reflect on the term $\left(z_{b}-1\right) \varphi_{b}$ and its relevance to what it is intended to be measured. If the intention is to order activities according to the resource pull attributable to protection, it seems that the term should be excluded from the calculation. Its inclusion could change the ordering of the epr measures without affecting the true resource pull, since the effects on other suppliers of changing the price of the nontradable good would be purely distributional (the good is not produced at the margin), that is, it would not be taken into account to determine the size of activity $c$.

On the other hand, if the intention is to focus on the income distribution effects of protection, those originating in changes in the prices of non-tradable joint products may be significant and attributable to the protection of $c$, affecting total retribution to domestic factors in the protected versus the free trade situations. In such cases, these price effects should be taken into account, especially if the focus were the relation between income distribution effects and political attitudes towards protection.

When there are nontradable joint outputs of $c$ that are produced at the margin by other nontradable activities, value added by the economy to produce a unit value of output by activity $c$ 
in the free trade situation would have to be adjusted for the same two effects considered before, only that now the price change $\left(z_{b}-1\right)$ would in general be different from the change in value added per unit, since tradable goods may also be used in the production of $b$. Let the change in the price of nontradable output $b$ be determined according to a simple input-output price model, i.e. it would be the result of the price effects of moving from the protected to the free trade situation on the total requirements of tradable inputs $s$ and nonproduced inputs $v$ :

$$
z_{b}=\sum_{s} a_{s b} \frac{(1+\delta)}{\left(1+t_{s}\right)}+\sum_{i} a_{i b} \Sigma_{s} \Sigma_{k} r_{k i} a_{s k} \frac{(1+\delta)}{\left(1+t_{s}\right)}+\sum_{v} f_{v b} z_{v}+\Sigma_{v} \Sigma_{k} r_{k b} f_{v k} z_{v}
$$

Expression [7] allows for the change in value added per unit value of production of $b$ resulting from moving from the protected to the free trade situation to be calculated as the new price, less the total requirements of tradable inputs revalued at free trade prices, less the total requirements of value added at protected prices, that is

$$
z_{b}-\Sigma_{s} a_{s b} \frac{(1+\delta)}{\left(1+t_{s}\right)}-\Sigma_{i} a_{i b} \Sigma_{s} \Sigma_{k} r_{k i} a_{s k} \frac{(1+\delta)}{\left(1+t_{s}\right)}-\Sigma_{v} f_{v b}+\Sigma_{v} \Sigma_{k} r_{k b} f_{v k}
$$

Expression [8] equals the increase in value added by nontradable activities per unit value of production of $b$, that is

$$
\sum_{v} f_{v b}\left(z_{v}-1\right)+\sum_{v} \sum_{k} r_{k b} f_{v k}\left(z_{v}-1\right)=\sum_{v} f_{v b}^{*}\left(z_{v}-1\right)
$$

where the * superscript indicates total requirements. As a result, value added by the economy in the free trade situation and attributable to the existence of activity $c$ would be 


$$
\begin{aligned}
v a_{c}^{f C}= & {\left[\frac{\left(1-\alpha_{b}\right)(1+\delta)}{\left(1+t_{j}\right)}+\alpha_{b} z_{b}-\Sigma_{s} a_{s c} \frac{(1+\delta)}{\left(1+t_{s}\right)}-\right.} \\
& \left.-\sum_{i} a_{i c} \Sigma_{s} \Sigma_{k} r_{k i} a_{s k} \frac{(1+\delta)}{\left(1+t_{s}\right)}+\Sigma_{v} f_{v b}^{*}\left(z_{v}-1\right) \varphi_{b}\right] \frac{1}{p_{n}^{f}}
\end{aligned}
$$

the value of all outputs in the free trade situation, less the value of direct and indirect tradable inputs, plus the change in value added per unit value of production in those other activities producing nontradable goods that are joint outputs of the protected activity $c$.

\section{Conclusions}

It is the productive activities of firms what is being protected by tariffs levied on their outputs (Corden, 1966). Thus, it is the effective protective rates of activities, not of individual outputs, what should be estimated. The paper provided the input-output formulas for calculating effective protective rates under the Balassa and Corden methods when there is joint production in fixed proportions, with special attention to the case when some joint outputs are nontradable. Since in the Balassa method measurement is restricted to value added by the activity, differences with the singleoutput activity are limited to properly valuing the output basket. In the case of Corden's method, instead, measuring valued added by the economy requires that the price effects associated with the joint production of nontradable outputs be also taken into account, which in turn requires that price changes attributable to moving from the protected to the free trade situation be estimated. 


\section{Footnotes}

* Inter-American Development Bank. Opinions expressed in this paper are those of the author and are not intended to represent the views of the Bank. Comments by G. Reed, S. Teitel, and an anonymous referee are gratefully acknowledged. The author remains solely responsible for the result

1. From a theoretical perspective, the free-trade counterfactual may result in switching to alternative techniques with different input and output compositions (Balassa, 1982, chapter 1; Corden, 1985, chapter 10). In practice, activity-level estimates of effective protective rates have to rely on existing coefficients, and therefore implicitly assume joint production in fixed proportions. Anderson (1998) proposes a general equilibrium measure of effective protection that includes the traditional measure as a special case.

2. $\quad$ "Ordinary normal tariffs apply to commodities, but resources move as between economic activities. Therefore, to discover the resource-allocation effects of a tariff structure one must calculate the protective rate for each activity" (Corden, 1966; 1985, p. 98).

3. $\quad$ "... under the so-called Balassa method, the effective rate of protection is estimated for the processing activity alone under the assumption that nontraded inputs are supplied at constant costs, where the cost of nontraded inputs is affected by protection-induced changes in the prices of tradable inputs used in the production of nontradable goods" (Balassa, 1982, p. 15). Equation [1] below, however, allows for changes in the prices of nontradable inputs through changes in prices of nonproduced inputs, and thus for better estimates of value added by the activity.

4. Some authors refer to this measure as "net" effective rate of protection because it accounts for the real depreciation required for moving from the protected to the free trade situation.

5. $\quad$ "... one must ask what the purpose of the effective protective rate concept is. The answer is that it should shed light on the direction of the resource-allocation effects of a protective structure" (Corden, 1966; 1985, p. 104).

6. Corden (1975) reviews the most important studies and Corden (1985, chapter 10) discusses the effects that may be expected from alternative assumptions.

7. See, for example, Balassa $(1971,1982)$.

8. In Greenaway et al. (1994), equation [4], "cost shares" $c_{i A}$ are calculated as $b_{i A} P_{i}^{W} / P_{M,}^{W}$, that is with respect to the principal output. Formulas equivalent to [4], but based on activity coefficients, are normally used to calculate effective rates of protection for industries producing several traded outputs. The same $c_{i A}$ coefficients are used by Greenaway et al. (1994) for the case of the "principal product only" - equation [5]-, where all costs are attributed to only one (or some) of the joint traded outputs. In practice, however, a frequent error is that of assuming that all outputs of an activity (or group of activities) are traded when some are not (the average tariff for the traded activities is used 
to correct the total value of production), rather than omitting one or more traded outputs and attributing all costs to the others.

9. Examples of normally nontradable joint outputs are straw from the production of grains, calfs from dairy farms, hides (to produce leather) and other by-products of slaughter houses, peels from the production of citric juice (used in the production of essential citric oils), and bagasse from the production of sugar (used in the production of paper).

10. Greenaway et al. (1994, p. 33) maintain that in "the logic of the Corden formulation ... nontraded inputs are ignored" and that it is "consistent with the Corden (and the Balassa) approach to assume that the domestic price of the nontraded output is not affected by the tariff structure". Ignoring the changes in the domestic prices of nontradable inputs would be an assumption consistent with Balassa's own statement (see footnote 2), but see Balassa (1982, pp. 16-7). In practice, however, there may be significant price effects associated to changes in the supply of goods that are nontraded and nonproduced at the margin. Corden pays detailed attention to price changes of nontradables and "primary factors" (Corden, 1966, section on Non-traded Inputs; Corden, 1971, sections 4.VIII and 7.I).

11. Note that in practice $Q_{i b}^{f}$ would have to be estimated from the protected situation, forcing to estimate the change in the production of $c$, and thus $b$, due to moving from the protected to the free trade situation. 


\section{References}

Anderson, J. (1998), "Effective Protection Redux", Journal of International Economics, Vol. 44, No. 1, pp. 21-44.

Balassa, B. and Associates (1971), The Structure of Protection in Developing Countries, Johns Hopkins University Press, Baltimore.

Balassa, B. and Associates (1982), Development Strategies in Semi-industrial Economies, Johns Hopkins University Press, Baltimore.

Corden, W. (1966), "The Structure of a Tariff System and the Effective Protective Rate", Journal of Political Economy, Vol. 74, No. 3, pp. 221-37. Reprinted in Corden (1985).

Corden, W. (1971), The Theory of Protection, Oxford University Press, Oxford.

Corden, W. (1975), "The Costs and Consequences of Protection: A Survey of Empirical Work", in P. Kenen (editor), International Trade and Finance. Frontiers for Research, Cambridge University Press, Cambridge.

Corden, W. (1985), Protection, Growth and Trade. Essays in International Economics, Basil Blackwell, Oxford.

Greenaway, D., G. Reed and R. Hassan (1994), "By-products and Effective Protection", Journal of Economic Studies, Vol. 21, No. 6, pp. 31-36. 